\title{
IDENTIFICATION OF THERMAL AND MICROSTRUCTURAL PROPERTIES OF HOT ROLLING SCALE
}

\author{
Badreddine Maalem ${ }^{1)}$ Djamel Berdjane ${ }^{\text {), }}$ Okba Belahssen ${ }^{2) *}$, Latifa Tairi ${ }^{1)}$, Youcef Faci ${ }^{\text {I), }}$ \\ Samira Djemili ${ }^{1)}$ \\ 1) Research Center in Industrial Technologies CRTI, P.O.Box 64, Cheraga 16014 Algiers, \\ Algeria \\ 2) Physics Laboratory of Thin Films and Applications (LPCMA), University of Biskra, 07000, \\ Algeria
}

Received: 31.07 .2019

Accepted: 22.08.2019

*Corresponding author: bel_okba@yahoo.fr, Tel: +21374637626, Physic Laboratory of Thin Films and Applications (LPCMA), University of Biskra, 07000, Algeria

\begin{abstract}
A significant amount of scale is produced during casting of ingots and processing of hot-rolled products. In manufacturing steel, during the various rolling operations, the amount of scale produced is approximately $0.1 \%$ of the annual production of the rolling mills. The quality of the thin sheet during rolling is affected by the behavior of the iron oxide layers formed on their surfaces. For this reason, acids and oils are used for the descaling of slabs and billets by means of pressurized water. The calamine, contaminated by these various acids and used oils, is rejected and stored involuntarily on important areas and pollutes soil and groundwater. Micrographic observations as well as X-ray diffraction analysis have shown that calamine consists mainly of iron oxides. Hematite and magnetite become the main components for oxidation times greater than 1 hour. Characterization tests have shown that calamine is dense $\left(\rho=4.8 \mathrm{~g} / \mathrm{cm}^{3}\right)$, its particle size is variable depending on the degree of oxidation (from 0.5 to $10 \mathrm{~mm}$ ). Simultaneous thermal analysis showed that an increase in mass of the calamine sample with a release of heat. Studies are underway for the physico-chemical characterization of the soils of the storage areas.
\end{abstract}

Keywords: Scale, risks, soil, thermal analysis, granulometry, X-ray diffraction

\section{Introduction}

Until the last decade, the scale, slag, dust and sludge generated by integrated steel plants wascalled waste, but now this term has been replaced with by-product and sometimes product due to intensive re-utilization of these materials. The management of all these substances generated in steel plants has become an important issue due to ever-tightening environmental regulations.

Mill scale is one of these materials produced in the processing of steel during continuous casting, reheating and hot rolling operations. Water sprays remove the scale formed during these operations and then mill scale is accumulated as a by-product in all iron and steel companies, either integrated iron and steel companies or mini steel mills and small mill shops.

Many researchers have found the structure and the thermal properties of scale formed during manufacturing of carbon steels were realized for a long time [1].

However, the research in this field was always actively studied by numerous specialists, in particular those of the steel industry [2]. 
In the steel-making manufactory, the flat products are hot-rolled. The quality of the thin sheet steel during the process of rolling is allocated by the formation of the layers of scale on the surface of the sheet steel to the cost all the operation of deformation along the hot rolling mill process. To minimize his growth inside the furnace, we have to respect certain necessary conditions among which the content in smokes which has to be between $1.5-2.5 \%$.

In the high-temperature heating of steel in pusher furnaces operating under traditional conditions with excess oxidant (usually ratio $\mathrm{n}=$ air/gas (1.1 to 1.3 ), three layers of oxides are formed on the surface of the steel.

The iron content is around $67 \%$, a large part of the scale is under magnetite and hematite, namely the oxygen content in the furnace. A certain amount of magnetite crystals will be present in the wüstite.

The degree of oxidation of the steel depends on the temperature, the chemical composition of the metal and the gas composition [3].

The steel where our scrap is collected is an extra-soft hot rolled low-carbon steel according to the international standard ISO 11949 for packaging called black iron, tinplate.

\section{Materials and methods}

The chemical compositions of the mill scale and the hot rolled steel are identified by SIEMENS SRS 3000 FRX analyzer. The composition is represented in Table 1.

Table 1 Chemical analysis of the hot rolled low-carbon steel

\begin{tabular}{|c|c|c|c|c|c|c|c|c|}
\hline Elements & & $\mathbf{C}$ & $\mathbf{M n}$ & $\mathbf{S i}$ & $\mathbf{S}$ & $\mathbf{P}$ & $\mathbf{A l}$ & $\mathbf{F e}$ \\
\hline$\%$ & & 0.09 & 0.35 & 0.04 & 0.025 & 0.025 & 0.05 & Balance \\
\hline
\end{tabular}

- The scanning electron microscopy analyses are carried out on scale scrap collected from the hot rolling mill and on polished surfaces of the same sample using ZEISS EVO-MA 25 scanning electron microscopy. Driven by integrated software where one can acquire micrographic results and chemical analysis by EDS.

The cooling system ensures proper functioning of the components to ensure a secondary vacuum, a $99.99 \%$ pure nitrogen bottle is connected to the equipment.

The principle of scanning electron microscopy is based on electron-matter interaction. The incident electron will interact with the nucleus, the more bound electrons of matter and the electrons of the outer layers $[4,5,6]$.

- AccuPyc II Series 1340 pycnometers are fast, fully automatic pycnometers that provide high-speed, high-precision volume measurements and true density calculations on a wide variety of powders, solids and slurries.

- The thermal analysis tests were performed by SDT Q600 V20.9 Build20 equipment. The sample holders used are made of alumina. The tests were carried out in a controlled atmosphere in order to avoid possible contamination of the samples. Among the advantages in operating curves, it gives the results coupled on a single graph for example DSC-TGA.

- The quantitative analysis of the constituents of calamine was determined using a rigaku diffractometer equipped with a copper anticathode tube. The diffraction pattern is made in the range 2 theta $10^{\circ}$ range at $90^{\circ}$ and with a scanning speed of $5{ }^{\circ} \mathrm{C} / \mathrm{min}$.

The instrument completes most sample analyses in less than three minutes without sacrificing accuracy. Once the analyses are started with a few keystrokes, the data is collected, the calculations made and the results displayed. Minimal operator attention is required. 


\section{Results and discussions}

The mill scale picked up by the hot rolling mill has a grey color. The result of his chemical analysis and granulometry dried at the temperature-time conditions $\left(\mathrm{T}=105^{\circ} \mathrm{C}, 24 \mathrm{~h}\right)$ are represented in the Tables 2 and 3.

Table 2 Chemical analysis of raw mill scale

\begin{tabular}{|c|c|c|c|c|c|c|c|c|c|}
\hline Elements & $\mathbf{F e}$ & $\mathbf{F e O}$ & $\mathbf{F e}_{2} \mathbf{O}_{\mathbf{3}}$ & $\mathbf{F e}_{3} \mathbf{O}_{\mathbf{4}}$ & $\mathbf{M n O}$ & $\mathbf{T i O}_{2}$ & $\mathbf{S i O}_{2}$ & $\mathbf{C a O}$ & $\mathbf{A l}_{2} \mathbf{O}_{3}$ \\
\hline$\%$ & 7.04 & 9.09 & 20.22 & 29.31 & 0.36 & 0.05 & 0.34 & 0.05 & 0.03 \\
\hline
\end{tabular}

Table 3 Results of granulometry analyzes of the raw mill-scale after drying at $105{ }^{\circ} \mathrm{C}-24 \mathrm{~h}$

\begin{tabular}{|c|c|c|c|}
\hline Size $[\boldsymbol{\mu m}]$ & Mass $[\mathbf{g}]$ & Rate[\%] & Cumul refuse[\%] \\
\hline$>200$ & 0.00 & 0.00 & 0.00 \\
\hline $125-200$ & 0.381 & 3.81 & 3.81 \\
\hline $90-125$ & 1.166 & 11.64 & 15.45 \\
\hline $63-90$ & 2.250 & 22.47 & 37.92 \\
\hline $45-63$ & 3.137 & 31.33 & 69.25 \\
\hline$<45$ & 3.079 & 30.75 & 100 \\
\hline Total & 10.013 & 100 & $/$ \\
\hline
\end{tabular}

The micrographs taken by scanning microscopy and for different magnifications show the microstructural appearance of laminated iron oxides in layers that are more or less large according to the phases and their distribution over the layer of scale formed (Figs. 1, 2).

Thus providing a motor element for the iron to spread through the hematite layer. The inner wüstite-iron interface has become corrected initially; then with the rapid advance of some protruding sections, some parts of the wüstite layer were reduced by first and ultimately the wüstite holding of the islands was reduced to complete the reduction process.

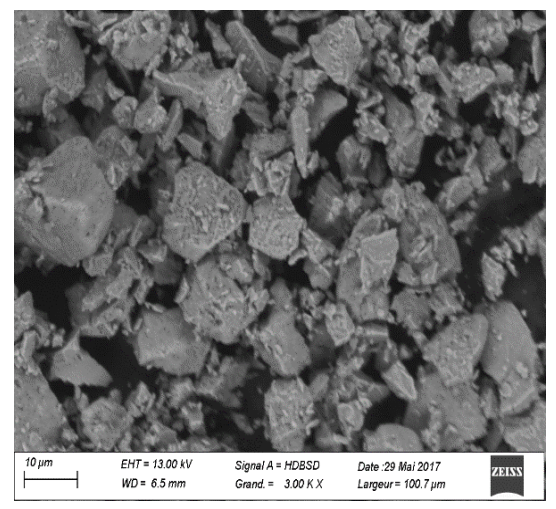

a)

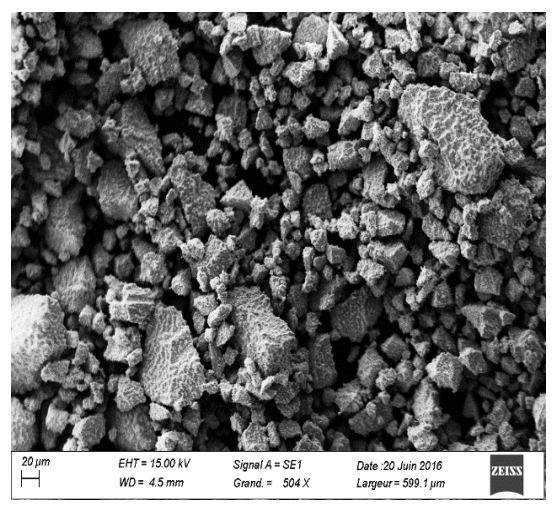

b)

Fig. 1 SEM micrographs showing obviously cluster's areas which iron oxides (a) raw scale, (b) scale after milling.

Porosities were produced when wüstite islands were reduced due to localized volume shrinkage. Higher oxygen concentrations in the underlying areas of the near-edge samples were assumed responsible for their slower reduction rates than those at the center $[7,8]$. 


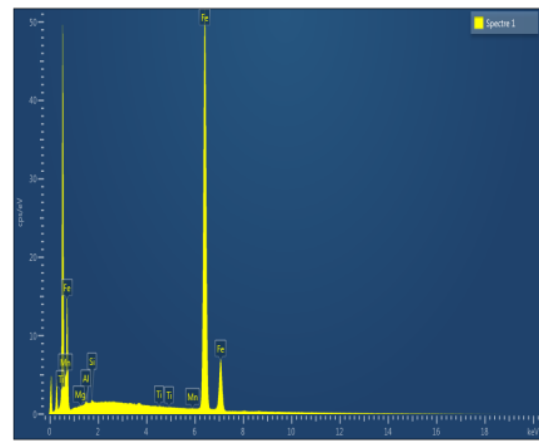

a)

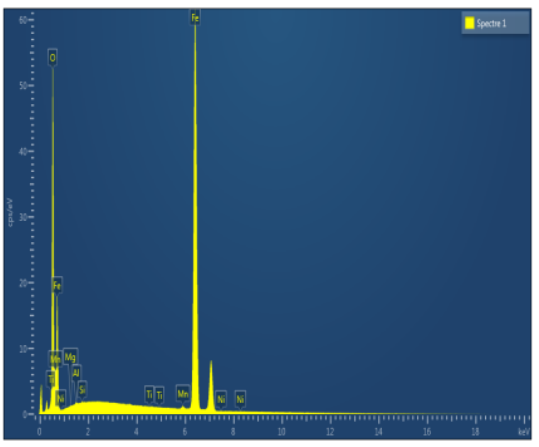

b)

Fig. 2 EDS of raw scale and scale after milling (a) raw scale, (b) scale after milling.

The pure iron scale is formed by three layers of superimposed oxides, corresponding to increasing levels of oxidation from the metal to the atmosphere, the layer of $\mathrm{FeO}$ protoxide against the metal, then the layer of magnetite $\mathrm{Fe}_{3} \mathrm{O}_{4}$, then a very thin layer of $\mathrm{Fe}_{2} \mathrm{O}_{3}$ hematite on the surface, these phases were confirmed by X-ray diffraction (Fig.3).

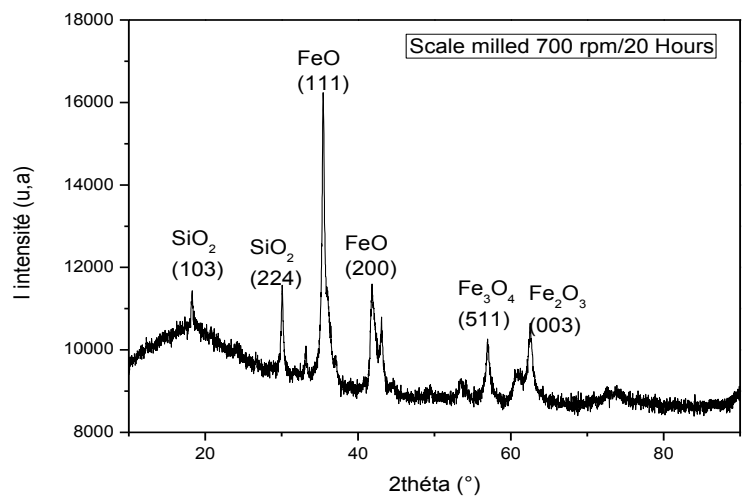

Fig. 3 X-Ray diffraction results of raw powder milling under $700 \mathrm{rpm}$ for $20 \mathrm{~h}$

An annealing at $\mathrm{T}=700{ }^{\circ} \mathrm{C}$ for $1 \mathrm{~h}$ with a heating rate from $20{ }^{\circ} \mathrm{C} / \mathrm{min}$ to that of maintenance is made for mill scale.

The heating rate adopted is $10{ }^{\circ} \mathrm{C} / \mathrm{min}$, which is swept from room temperature to $\mathrm{T}=1100{ }^{\circ} \mathrm{C}$. The choice of rise of temperature is based on findings revealed on work carried out in this direction and which proved conclusive technical results $[10,11]$.

On the thermal analysis curves, we can observe the appearance of peaks; we have two peaks, one endothermic at $\mathrm{T}=340{ }^{\circ} \mathrm{C}$ and the other exothermic at $\mathrm{T}=570{ }^{\circ} \mathrm{C}$.

The endothermic peak represents the transformation of $\gamma-\mathrm{Fe}_{2} \mathrm{O}_{3}$ to $\alpha-\mathrm{Fe}_{2} \mathrm{O}_{3}$. However, at the exothermic peak at $\mathrm{T}=570{ }^{\circ} \mathrm{C}$, a process of beginning of rearrangement of the grains is what is called a primary recrystallization, which takes that the transformation beginning of wüstite to magnetite took place in Fig. 4. Above $\mathrm{T}=1000{ }^{\circ} \mathrm{C}$, the trend of the heat flow curves and that of DSC is not perfectly clear. From a stability point of view, a steady state will be established in Fig. 4. A slight peak can be seen at $\mathrm{T}=570{ }^{\circ} \mathrm{C}$ in Fig. 5 . 
For the sample which has been annealed at $\mathrm{T}=580{ }^{\circ} \mathrm{C}$ for 2 hours with heating rate from 20 ${ }^{\circ} \mathrm{C} / \mathrm{min}$ to the holding temperature followed by oven cooling small size grain of oxides has been confirmed. In figure 5, the loss of mass takes a linear appearance from $\mathrm{T}=600{ }^{\circ} \mathrm{C}$ to $\mathrm{T}=1100$ ${ }^{\circ} \mathrm{C}$.

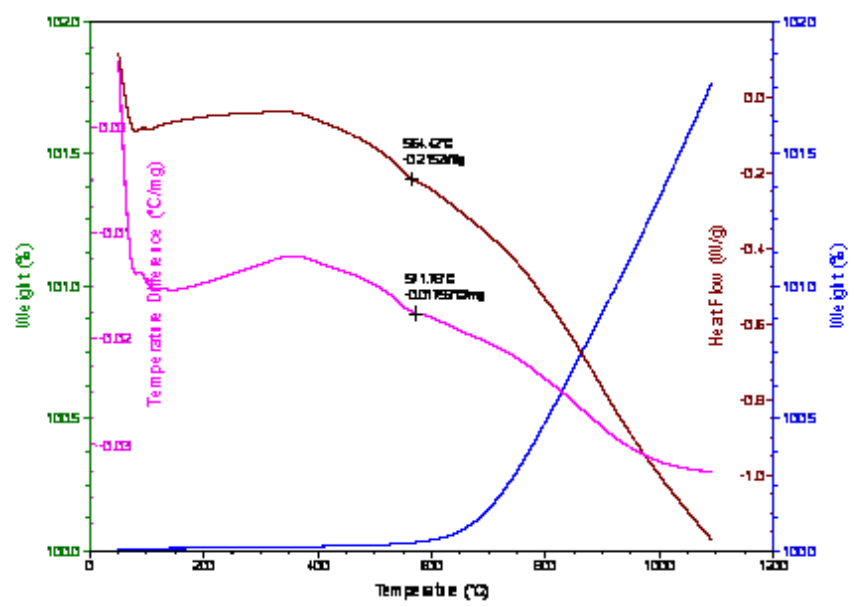

Fig. 4 DSC-TGA of the studied raw scale.

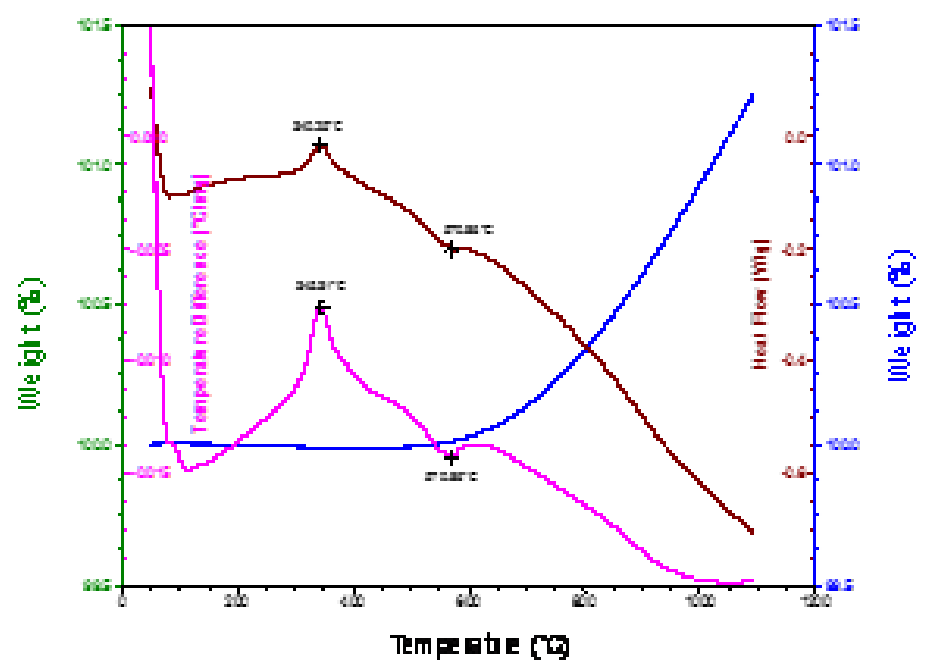

Fig. 5 DSC-TGA of the studied mill scale treated at $\mathrm{T}=700{ }^{\circ} \mathrm{C}$

\section{Conclusion}

This study allowed us to identify the thermal and microstructural properties of calamine from the hot rolling mill for later exploitation in the industrial field.

These oxides are confirmed with X-ray technique which their shape and dispersion were been obviously seen in SEM with different magnificent. 
The chemical analysis shows a total iron of the order of $67 \%$ with other oxides in trace.

The particle size of the powder has an average diameter of the order of $50 \mu \mathrm{m}$ and with wet and dry densities respectively 5.42 and $5.67 \mathrm{~g} / \mathrm{cm}^{3}$. The presence of silicon was confirmed by X-ray analysis and the most phases common are magnetite and hematite and the SEM micrograhs corroborate their allocation. The presence of silicon is confirmed by EDS analysis.

\section{References}

[1] L. A. Shult's, Reducing the High-Temperature Loss of Steel in Furnaces, Steel in Translation, Vol. 46, 2016, No. 7, p. 467-473, http://dx.doi.org/10.3103/S0967091216070123

[2] C. Eyraud and A. Accary, Analyses thermique et calorimétrique différentielles, Traité Analyse et caractérisation, number PE 1295, pp.1-14, 1992. Techniques de l'ingénieur, 1992.

[3] M. Grafoute, Etude Des Propriétés Structurales et Modélisations de Poudres Nanostructurées de Fer obtenues par Broyage Mécanique, thèse de doctorat, Université du Maine, France, 2004. http://pecbip2.univ-lemans.fr/docpdf/theseMG.pdf

[4] S. Chandra, K. Ngamkham, N. Jiratthanakul, Effects of Process Parameters on Mechanical Adhesion of Thermal Oxide Scales on Hot-Rolled Low Carbon Steels, Oxid Met, Vol. 80, 2013, p. 61-72, http://dx.doi.org/10.1007/s11085-013-9370-6

[5] M. Krzyzanowski, J.H. Beynon, D.C. Farrugia, Oxide Scale Behavior in High Temperature Metal Pressing, Wiley \& Sons, Weinheim, 2010, http://dx.doi.org/10.1002/9783527630318

[6] D. Genève, D. Rouxela, P. Pigeata, M. Confente, Descaling ability of low-alloy steel wires depending on composition and rolling process, Corrosion Science, Vol. 52, 2009, p. 1155 1166, http://dx.doi.org/10.1016/j.corsci.2009.12.028

[7] J. Xu, Kinetics of Wüstite Formation and Reduction of Manganese alloyed Steel, Master Thesis, Delft University of Technology, Netherlands, 2013. http://resolver.tudelft.nl/uuid:47957f9e-8ee2-4c00-9cb8-9bbd49b7c7f9

[8] R.Y. Chen, Mechanism of Iron Oxide Scale Reduction in 5\%H2-N2 Gas at 650-900 ${ }^{\circ} \mathrm{C}$, Oxid Met, Vol. 88, 2017, No.5-6, p. 687-717, http://dx.doi.org/10.1007/s11085-017-9769-6

[9] G. Naveen Kumar, Y.V. Mohana Reddy, K. Hemachandra, Reddy Synthesis and characterization of iron oxide nanoparticles reinforced polyester/nanocomposites, International Journal of Scientific and Research Publications, Vol. 5, 2015, No. 8, p.1-13, doi. ISSN 2250-3153

[10] S. Ahmed Al-Kadya, M. Gaber, M. Hussein, B. El-Zeiny, M. Ebeida, Structural and fluorescence quenching characterization of hematite nanoparticles, Spectrochimica Acta, Vol. 83, 2011, p. 398-405, http://dx.doi.org/10.1016/j.saa.2011.08.052

[11] S. Chandra-ambhorn, T. Nilsonthi, Y. Wouters, A. Galerie, Oxidation Kinetics, Mechanical Adhesion and Pickling Behaviour of Thermal Oxide Scales on Hot-rolled Conventional and Recycled Steels, Steel Research International, Vol. 81, 2010, No. 9, p. 130-133, http://dx.doi.org/ 10.4028/www.scientificnet MSF.696.170 